\title{
Energy Efficient and Low-Carbon Technology in Process Industries: Innovation, Diffusion and the Role of Public Policy
}

\author{
Anna Mansikkasalo, Ph.D. Candidate in Economics, Luleå University of Technology, Sweden, and \\ Patrik Söderholm, Professor of Economics, Luleå University of Technology, Sweden
}

\begin{abstract}
This paper addresses the role of public policy in influencing technological innovation and diffusion in the energyintensive process industries (e.g., pulp and paper, iron and steel etc.). We highlight in particular technologies that either reduce the industry's energy use or imply lower process emissions of carbon dioxide. This research scope is motivated due both to its societal relevance and the fact that it raises a number of important scientific challenges and controversies. Specifically, the paper discusses the role of two different theoretical perspectives for orienting the analysis of issues in technology policy: the neoclassical and the evolutionary approaches. The overall objectives of the paper are to: (a) provide a conceptual comparison of these theoretical approaches and their implications for the role and the design of policy intervention; and (b) discuss some relevant implications for spurring innovation processes by examining the experiences of two existing policies and one future technological challenge (CCS) in the Swedish process industries.
\end{abstract}

Index Terms-environmental economics; global warming; innovation management; manufacturing industries; research and development management; sustainable development; technical innovation.

\section{NOMENCLATURE}

CCS: carbon capture and storage

PFE: Program for energy efficiency in Swedish industry

R\&D: research and development

\section{INTRODUCTION}

$\mathrm{T}_{\mathrm{t}}$ HE promotion of innovation and technology diffusion in the energy and environmental field concerns not only technical challenges, but it is also largely a matter of economic forces, policy incentives and institutional obstacles. This paper addresses the issue of how to design public policy to stimulate technological innovation as well as the diffusion of carbon-free and energy efficient technology in process industries. Empirically we pay particular attention to the Swedish process industry.

An important starting point for the analysis is that the scien-

This work has been supported by the Swedish Energy Agency, Vattenfall and the Ragnar Söderberg Research Foundation.

A. Mansikkasalo is with Luleå University of Technology, 97187 Luleå, Sweden (e-mail: anna.mansikkasalo@1tu.se).

P. Söderholm is with Luleå University of Technology, 97187 Luleå, Sweden (e-mail: patrik.soderholm@ltu.se). tific literature offers little overall empirical and theoretical consensus when it comes to the choice of specific technology policy instruments [12]. For this reason we highlight the implications drawn from two theoretical frameworks: neoclassical economic theory and the institutional or evolutionary approach to technology policy. The former primarily views innovation policy as dealing with the free market's inability to allocate innovation resources efficiently [23], while the latter sees appropriate innovation policy primarily as building or maintaining effective innovation systems [20]. Thus, these two approaches rely on different perspectives about (not the least) the context within which innovation activities take place, and they therefore sometimes result in diverging lessons for policy implementation and design.

In the paper we apply the Schumpeterian trichotomy and view innovation as the phase in which technical inventions are made available on the market. Hence, organizational and/or institutional innovations are not considered here. Technology diffusion refers to the phase of the technological change process in which the technology becomes widely available for use [3]. In the paper we address both the innovation and the diffusion phase, while the invention phase is left out.

An important challenge for technology policy is therefore to determine under which circumstances the government ought to intervene and promote certain technologies [19]. The neoclassical perspective emphasizes the need for framework conditions (i.e., to address market failures) rather than targeting specific sectors or technologies, while an essential component of the evolutionary approach is to review and redesign the interrelations between the different components of the innovation system. In the latter case, therefore, failures may extend beyond those identified in the neoclassical analysis to subsume failures of institutions to coordinate, link or address various needs [14].

In the next section we provide a more in-depth conceptual analysis and a comparison of the role of technology policy as outlined in the neoclassical economics field and the innovation system literature, respectively. Section IV applies these analytical perspectives to discuss two empirical experiences of policy compliance and innovation in Swedish process industries: (a) the voluntary energy efficiency program PFE; and (b) the environmental permitting system. In section $\mathrm{V}$ we briefly discuss some lessons for the introduction of the CCS technology 
in the industrial sector, while section VI concludes the paper.

\section{The ROLE OF TEChNOLOGY POLICY: TWO PARADIGMS}

Below we compare the above theoretical frameworks for orienting analysis of issues in technology policy. Our comparison identifies and analyzes a set of important differences, including tentatively the respective conceptions of: (a) the context for economic behavior and the concept of rationality; (b) the way to address the institutional complexity of a specific sector or the entire economy; and (c) how efficient economic performance (including innovation activity) is defined and evaluated. These differences also imply diverging views on the role and the scope of technology policy in the environmental and energy field [21].

\section{A. The Context for Economic Behavior and Rationality}

The evolutionary literature explicitly acknowledges the dynamic evolution of the economy with constant innovation activities taking place (in large inspired by Schumpeter [22]), while the neoclassical approach is more static and builds on a view of the economy as an equilibrium configuration undergoing well-anticipated change over time. Thus, in the latter case economic actors essentially understand fully the context within which they operate and are able to choose among all available options, while the evolutionary approach pays more attention to the potential bounded rationality of, for instance, firms. Bounded rationality implies that individuals within firms will economize on scarce cognitive resources by utilizing routines and rules of thumb and will tend to make satisfactory decisions rather than expend time and effort searching for the optimum decision [5].

This has implications for the ways in which the two paradigms approach the process of technological change. In the neoclassical case the focus is on the long-run equilibrium and thus on the presence of decreasing returns to scale. In contrast, the evolutionary paradigm emphasizes the presence of increasing returns to scale and the mechanisms that create such returns, including learning economies, adaptive expectations, and network economies. An important implication of this is that inferior technical designs can become locked-in through a path-dependent process. Unlike an efficient market with fully informed and rational actors that select the optimal technology, the superior technology does not necessarily win out in such a framework. Thus, within the evolutionary paradigm it is argued that the logic of a dominant design can be so pervasive that it becomes imprinted in the firm's organizational structure. Therefore, within these organizational silos 'rules of thumb' or standard operating procedures emerge [13]. Such 'behavioural failures' have been shown to explain the industry's limited attention to cost-effective energy efficiency measures [26]

\section{B. Institutional Complexity and Efficient Performance}

In the case of how the two different paradigms address the institutional complexity of the economy, it is worth noting that in the neoclassical case the role for technology policy is seen as a response to the presence of 'market failures' in the production and commercialization of new knowledge. These failures include, for instance, the positive externalities (spill- overs) that characterize $\mathrm{R} \& \mathrm{D}$ and learning activities [10], but also problems of asymmetric information and network externalities. Within this approach an explicit distinction is therefore made between market and non-market behaviour (e.g., private $\mathrm{R} \& \mathrm{D}$ efforts). The neoclassical framework prescribes an important role for public policy only in those cases where the market 'fails,' and thus offers distorted incentives which are inconsistent with economically efficient outcomes. In the evolutionary approach, though, it is emphasized that the distinction between market and non-market outcomes is much more blurred, and one must instead address the complex and varied set of actors and institutional arrangements that affect the pace and the pattern of technological innovation [21]. This implies, for instance, that public R\&D and technology policies form part of the innovation system, and any new policy measure or alteration of existing policies should, it is argued, address the policy's appropriate role in this system.

Evolutionary theorists do typically not regard innovation and diffusion as separate activities; instead they are perceived to be inseparable. Diffusion will affect future innovations (the re-development of a technology) through learning and vice versa. This is why the evolutionary paradigm tends to highlight that technology policy needs to build upon insights drawn from specific contexts, and best-practice can thus typically not be translated from one innovation system to another [19]. Unlike in the neoclassical case it is important not only to protect the suppliers of knowledge (e.g., through patents), but to pay equal attention to other types of actors and to important linkages between these. According to this view, policy is subjectively designed and may not necessarily be founded on superior knowledge. Hence, just as a given technological strategy may fail, policies may fail as well.

The above implies thus that the rationale for government intervention differs between these two paradigms. According to the evolutionary approach there is an inbuilt restlessness in the economy, and this is the result of the process of continued learning and application of knowledge into new situations in search for profit opportunities. In this setting, it is argued, information has to be asymmetrically distributed if opportunities for supernormal profits are to exist. In contrast, within the neoclassical paradigm asymmetries in information and knowledge give rise to inefficiencies, e.g., they result in parallel R\&D efforts, while in the evolutionary approach this is an effective way of exploring technological opportunities [11].

\section{The Diffusion of Energy Efficient Technology: Combined Insights}

An important starting point for our investigation of specific policy instruments in the energy field is that both of these research paradigms offer important insights into the environmental innovation process, as well as into the role of technology policies.

Figure 1 attempts to provide a formal illustration of some of the key points using a neoclassical framework. The relationship between firm output $(q)$ and energy use $(e)$ is described by a production function $f(e)$, where $f_{0}$ represents the production function at the time before any policy targeting energy efficiency is implemented [25]. A profit-maximizing firm in 
the pre-policy period will choose to use $e_{0}$ units of energy, resulting in a profit level at $\pi_{0}$. If the policy imposes a limit on energy use, from $e_{0}$ to $e_{1}$, this will restrict the firm's production possibilities and lead to lower profits. In Figure 1 this is illustrated by a move from A to C. According to the neoclassical view this would be the main outcome in the absence of any information asymmetries or any other market failures.

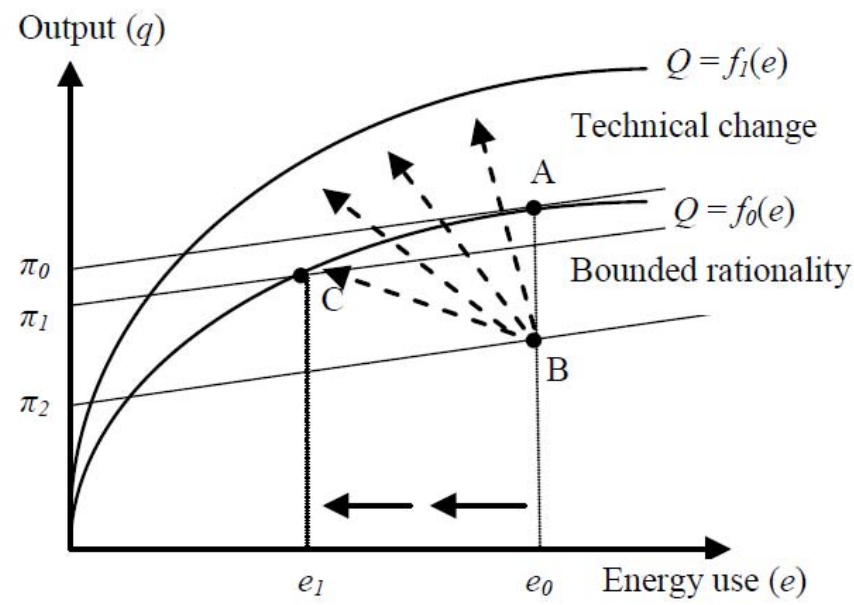

Figure 1: Energy Efficiency and Technology Policy

However, the evolutionary approach would stress that with the implementation of the policy two additional things may occur. First, if designed properly the policy could reveal important inefficiencies in the firm's use of energy inputs. One way to illustrate this is to assume that during the pre-policy period the firm is not producing at the production possibility frontier but rather at point B (making a low profit, $\pi_{2}$ ). By explicitly highlighting these inefficiencies (i.e., by inducing the firm to undertake more search activities in order to identify these itself), the firm could move closer to the production frontier and generate higher profits (e.g., $\pi_{l}$ at point $\mathrm{C}$ ).

Second, the policy may also have dynamic effects in that it stimulates innovation and the diffusion of new and more efficient production processes. Figure 1 illustrates this by outlining a new production technology $f_{l}$, permitting more output for each level of energy use. However, at the same time we have continuous innovation and exogenous technical change that make it difficult to isolate the policy-induced innovation from that occurring already in a baseline scenario. The new production function $f_{l}$ is thus a result of both policy and other factors. The uncertain total effect on output and energy use is illustrated by the dashed arrows in Figure 1. This 'restlessness' in the economy is acknowledged by both theoretical paradigms but more heavily emphasized in the evolutionary approach.

The evolutionary approach emphasizes that technology policy has an important role to play in directing future technical change. The future innovation path is highly uncertain and there is a need for policy to find its appropriate role in the innovation system. Typically this means that technology policy cannot be entirely technology-neutral, and there is often a case for coordinating energy and environmental policies with, for instance, specific public R\&D projects. It could also be important to permit firms flexibility over time in complying with new energy efficiency or environmental targets (e.g., through the use of extended probation periods). The gradual diffusion of a certain technology can reveal areas where additional R\&D would be most productive. While the neoclassical perspective will point out the presence of general knowledge externalities (spillovers), the information feedback from diffusion to innovation - e.g., so-called learning spillovers - will often be important in practice.

In section IV we discuss the impacts on technical change of two different - but closely related - policy instruments that affect the diffusion of energy efficient technology i $\pi_{0} \mathrm{n}$ Swedish process industries (e.g., pulp and paper, mining, iron and steel etc.). These include the voluntary energy efficiency program PFE, and the environmental permitting system under the so-called Environmental Code. In the latter case we also discuss the experiences of permitting Swedish industry in the past. We suggest that there is likely to be no single best policy instrument to foster innovation in the energy and environmental field, but an important role for policy is to provide incentives for both supply- and demand-driven innovation.

\section{ENERGY EFFICIENCY AND ENVIRONMENTAL PERFORMANCE IN THE PROCESS INDUSTRY: Two POLICIES}

The Swedish program (PFE) has provided energy-intensive companies the opportunity of a reduced tax on electricity use. In return they have had to introduce and obtain certification for a standardized energy management system and carry out an energy audit. The latter has been done to identify specific energy efficiency measures to be implemented in subsequent years as long as these have a pay-back time of less than three years [6]. Participation is voluntary, but the program has only been open for energy-intensive companies (i.e., implying that the cost of energy in the company amounts to at least 3 percent of the value of the output).

Energy efficiency also represents one of the objectives of the Swedish Environmental Code, and it is part of the 'best available technology' requirement in the so-called IPPC Directive (as well as in the recently adopted industrial emissions Directive). Unlike PFE, the requirements under the Code may concern all types of energy use (and thus not only electricity). The Environmental Court of Appeal has in several cases examined and stipulated measures for energy conservation in major industrial facilities in Sweden. The terms are often of a general nature and therefore flexible, but there is often a lack of legal certainty. There are also sentences in which the conditions are more specific, including maximum energy use values.

Industry representatives typically argue that efficient energy use is best promoted through technology-neutral policy instruments such as PFE, rather than by the firm-specific permitting processes that follow with the Environmental Code [26].

\section{A. The Voluntary Energy Efficiency Program PFE}

On 1 July 2004, due to the adoption of the EU's Energy Tax Directive, a tax of 0.005 SEK per kWh (EUR 0.5 per 
MWh) on industrial process-related electricity was introduced. The Directive gives, however, the energy-intensive companies that are subject to the tax, the opportunity of reduced taxation on their electricity consumption if they take action to improve their energy efficiency. As an instrument to promote this, the program for improving energy efficiency (PFE) came into force in January 2005.

The net effect on electricity use of these types of programs is often uncertain. Neoclassical economic theory suggests that the decrease in the electricity price following the tax exemption will (ceteris paribus) lead to increased electricity use. On the other hand, different market failures that motivate policy intervention targeting increased energy efficiency could exist, thus stimulating measures beyond those already taking place in the market. For instance, the presence of asymmetric information, implying that one actor holds information but faces too few incentives to transfer this to other actors although this would increase overall economic efficiency, may lead to an inefficient (and too high) electricity use [8]. One example is the principal-agent problem where the principal (e.g., the CEO) is unable to perfectly monitor the agents' (e.g., the engineers') performance and introduce strong enough incentives for these to pursue all profitable energy saving projects.

Moreover, the evolutionary literature stresses that organizations develop patterns of behaviour, often referred to as routines or set of rules, to respond to different problems as they arise [16]. Once a set of rules is developed it is reinforced by, for instance, in-house training and various incentive structures. Thus, bounded rationality can imply that a set of rules or problem-solving techniques within the firm will persist since they are costly to change but also because the system itself is not questioned. This may potentially motivate the use of policy instruments such as PFE that raise firms' attention to energy use issues.

The above implies that compared to a unit electricity tax, an important condition for a voluntary agreement scheme such as PFE inducing overall lower electricity use is that there is evidence of information or behavioural inefficiencies in the tax case leading the relevant firms to forego otherwise profitable investments.

Under PFE the firms have had to introduce and obtain certification for a standardized energy management system (EMS), and carry out an energy audit and analysis. The purpose of the energy audit and analysis has been to enable the firms to identify measures that improve the efficiency of its electricity use. These measures should have a pay-back time of less than three years. If the firms have achieved an improvement in electricity efficiency which, broadly speaking, is equivalent to the improvement which would have been achieved if the tax had been imposed, then the firms will have fulfilled its obligations under the program [27]. In other words, PFE builds on the presumption that the attention-raising effect of the program on electricity use will (at least) overweigh the positive impacts on electricity use following the electricity tax exemption.

In her dissertation Henriksson [27] investigates the own- price elasticities of electricity demand in Swedish industry (pulp and paper as well as mining). Her results suggest fairly low electricity using impacts following the removal of the EU minimum tax compared to the self-reported electricity savings in PFE. For instance, in the mining industry the results of the first program period of PFE indicated a self-reported reduction in electricity use by almost 12 per cent (corresponding to about $0.2 \mathrm{TWh}$ ). The estimated long-run own-price elasticity of electricity demand in this industry indicates in turn that (with the year 2005 used as baseline) the associated tax relief would only induce a corresponding increase in electricity use by about 4 per cent.

Taken at face value this comparison suggests that the attention-raising effect of PFE with respect to previously unattended energy efficiency measures will dominate over the price effect following the tax relief. However, a number of complications make this conclusion less certain.

First, the presence of, for instance, information asymmetries imply that energy management system could be more effective in companies with a less energy-intensive production process due to the lack of prior experience of energy efficiency measures in these firms. However, the current set-up of PFE induces the reverse situation, stimulating participation mainly among companies that have a high electricity cost share and therefore have faced considerable incentives in the past to lower electricity use [6].

Second, the empirical results also show that already prior to the implementation of PFE Swedish industrial firms have invested in private $R \& D$, and they have in this way accumulated knowledge that have had electricity saving impacts [28]. In other words, already in a baseline setting industry strategies include search processes that tend to result in lower electricity use per output produced. While PFE and similar voluntary energy efficiency programs may add to these types of activities future evaluations of the outcomes of such programs must increasingly recognize the already prevailing incentives to improve energy efficiency in electricity-intensive industries. The above also highlights the importance of distinguishing between the incentives faced by firms in the absence versus the presence of specific public policy measures, as stressed in the neoclassical economics literature.

Third and finally, the program's impact on innovation may be limited. In industry electricity efficiency improvements are typically embodied in the diffusion of new capital equipment. A far from insignificant fraction of the efficiency measures that have been induced by PFE may simply represent economically inefficient increases in capital turnover. In other words, PFE contributes to a 'catch-up' effect in that inefficient firms are encouraged to move closer to best-practice firms (i.e., the production frontier). One relevant example in the pulp and paper industry is the substitution of more efficient electric motors for less efficient ones, a measure which has been undertaken at least in 85 cases during the program's first period [28]. This will spur innovation only if there are considerable economies of learning associated with these investments, but empirically it remains unclear if this can be anticipated in the above case. 
The above suggests that from a technology policy perspective PFE could benefit from a stronger emphasis on measures that spur technological progress and thus move the production frontier. This could possibly be achieved by granting firms more flexibility over time in investigating different potentially efficient measures, and by supporting relevant $R \& D$ projects that are advanced incrementally in interaction between the industry, the environmental authorities and research institutes. Although this would imply a stronger emphasis on a 'picking winners' policy it could be necessary to promote innovation in the industry, and would provide a direct catalyst to the compliance process in PFE.

Still, this does not preclude the fact that important evidence of bounded rationality may exist. Studies of other previous programs of a similar kind (e.g., [7]) suggest that industrial firms often reject opportunities to save energy even if those meet reasonable rate-of-return requirements. Thus, these studies suggest that voluntary efficiency programs tend to achieve documented successes that cannot be reconciled with the view that energy use decisions are made in efficient markets. Firms may therefore be better understood as networks of individuals linked together by flows of information and materials than as profit-maximizing units. As such, the firm owners and senior managers remain profit-oriented but are unable to achieve the ideal of profit maximization given information asymmetries and the bounded rationality of the people who constitute their organization.

\section{B. Environmental Permitting and the Environmental Code}

According to the Swedish Environmental Code industrial facilities can only be permitted if they are in compliance with certain environmental requirements, and these may include demands for energy efficiency measures. Thus, and as was noted above, energy conservation is one of the objectives of the Code, and it is also part of the "best available technology" requirement in the so-called IPPC Directive.

The Code does include provisions for the weighting between different interests, but these are however vaguely formulated, and therefore provide substantial scope for different interpretations regarding the legal application. Industry representatives therefore frequently state that the individual permit conditions are uncertain and may differ a lot across similar types of industrial facilities.

The relationship between the Environmental Code and PFE is controversial. Legally PFE is often seen as a complement to the permit conditions. The Code allows, however, demands for other types of - as well as more far-reaching - energy efficiency measures, and EU law does not permit PFE to replace the case-by-case assessment according the Environmental Code.

In an earlier report [26] we show that the Environmental Code and PFE in combination imply a form of dual control of energy conservation behavior in Swedish industry; there exists therefore a need to "streamline" these two instruments. The Environmental Code can constitute the main regulation for determining the conditions for the operation of existing and new industrial facilities. It permits flexibility in terms of adjusting conditions to meet the specific situations that face each industrial plant, and also provides scope for initiating important technology search activities at the plant level.

The industry's criticism of the Code should however be taken seriously. A number of revisions could make the environmental permitting process more efficient, such as: (a) the development of specific guidelines for how assessments should be performed in preparation for permits; and (b) the establishment of a forum for more constructive dialogue between regulators and industry representatives. On the latter point the regulating authorities need to overcome the often significant information asymmetries. An efficient individual permitting process builds heavily on a common understanding of the problems, opportunities, and the challenges that exist in each case, but this is often lacking today. As stressed in the evolutionary paradigm it is useful for policy to identify its role in the innovation system.

As in the case of PFE, the permitting conditions according to the Environmental Code may only stimulate the diffusion of incremental improvements in the production processes and thus have limited innovation impacts. Interestingly this is in sharp contrast to the environmental permitting process during the 1970s and the 1980s in Sweden. During this period the emissions of a large number of hazardous substances (e.g., sulphur dioxide, COD, heavy metals etc.) decreased significantly in Swedish industry (e.g., in the pulp and paper and in metal smelting sectors). The Swedish regulatory approach relied heavily on the use of performance standards, a long-term strategy on environmental innovation, as well as on close firmregulator negotiations making use of both decentralized knowledge and jointly funded research programs [24]. During this period Sweden adopted a slower but at the same time more cooperative and long-term pollution control strategy compared to, for instance, USA and Canada [18].

Specifically: (a) the regulations built heavily on performance standards thus granting substantial flexibility to industrial plants in terms of selecting the appropriate compliance measures; and (b) joint public-private R\&D efforts to develop and improve pollution abatement technologies. The environmental authorities granted firms probation periods during which industry was given the opportunity to develop and test new solutions. This was typically done in close cooperation with other firms, research organizations, consultants and suppliers within the realms of large jointly funded $\mathrm{R} \& \mathrm{D}$ projects [2]. The flexibility granted in terms of compliance and time strategies provided scope for identifying solutions that were deemed to be attractive over the long-run, and it also enabled the companies to coordinate pollution abatement measures with productive investments.

In many cases it also led to important technological breakthroughs at the firm level. For instance, the Swedish metal smelter Rönnskär (owned by Boliden) became a world leader in mercury and arsenic abatement technology as well as in the abatement of heavy metals from water. Some of the performance standards were genuinely 'technology-forcing' in that they built on assessments of technologies not yet fully deve- 
loped. For instance, in the pulp and paper industry this was evident in the chlorine question [24].

Thus, new knowledge was advanced incrementally within the system in close interaction with the environmental authorities, and the industry, and industry-wide R\&D projects were often already in full swing or planned for as new technology were suggested by government authorities in connection to individual licensing processes. Moreover, the use of probation periods also likely increased the regulatory system's legitimacy.

However, the Swedish approach of the 1970s and the 1980s was at the same time demanding in that it relied on high regulatory competence and intensive information-sharing between the involved parties. This implies that the extent of firm-regulator information asymmetries was relatively limited, and new knowledge, e.g., developed in research programs, was effecttively used by the authorities in upcoming licensing processes. It may be noted that in the 1970s the Swedish Environmental Protection Agency, a key actor in the permitting process, hosted an entire research department focusing solely on addressing pollution problems from process industries. During 2011 the same authority had only one full-time employee solely responsible for inspecting the entire pulp and paper industry in the country. This is likely to reduce the regulator's current opportunities for achieving deep emissions reductions and radical energy efficiency improvements.

The experiences from the Swedish case illustrate that key implications from the neoclassical environmental economics literature (e.g., flexibility in compliance measures, strategies to reduce firm-regulator information asymmetries etc.) are useful for understanding how environmental compliance and innovation can be promoted in an efficient manner. However, these experiences also illustrate that there is typically no simple, one-directional (stimulus-response) link between the regulator and the regulated firms, and compliance and innovation are typically affected by multiple policies within a complex network of actors (see also [9]). This observation is well in line with the evolutionary approach to technology policy.

In addition, in practice there is not necessarily any clear view on what is meant by efficient outcomes since the regulatory process involves important trade-offs. Most notably, pollution control and energy efficiency policies need to maintain strong, continuous incentives for compliance and innovation while at the same time taking into account the risk of excessive compliance costs for those affected by the policies.

\section{The DifFusion of CARbon CAPTURE AND StORAGE}

The discussion so far has focused on achieving improved energy efficiency in existing process industries. In this section, though, we address the challenges involved in introducing an entirely new techno-logy in the industrial sector, namely socalled carbon capture an storage (CCS). As argued below, this is a technology that will require specific policy attention, and where thus technology-neutral policies - such as carbon pricing - may only constitute one component of a rather comprehensive policy portfolio.
CCS has been acknowledged as an important option to mitigate carbon dioxide emissions and reach climate targets. So far, the focus of the political CCS discussion has been set on the power sector. However, for some carbon-intensive industries CCS could be a valuable solution as for the time being a significant amount of emissions from industry is process related and is difficult to mitigate. Industries account for about 22 per cent of the carbon dioxide emissions of the European Union; globally industrial carbon dioxide emissions are much higher with about 40 per cent. Still, the introduction of CCS will not come without complications, and therefore raises a number of important technology policy issues.

Previous work (e.g., [1]) has evaluated and compared CCS deployments in different countries, including USA, Canada, Norway, the Netherlands and Australia. This research indicates that large amounts of CCS-related knowledge, accumulated in networks of actors, remain unutilized and is not employed by entrepreneurs to investigate different market potentials for CCS. For this reason the CCS innovation system may have entered a critical phase; in order to move the development forward and towards a broad-scale implementation of the technology a number of different policy efforts are needed. Direct policy initiatives targeted against weak innovation system functions, such as entrepreneurial activities, market creation and mobilization of resources are likely to be necessary. Some countries also need to provide more regulatory guidance and improve the overall legitimacy of the technology.

The central problem is that new technologies, such as CCS, often remain unable to negotiate the various market and institutional barriers that confront them. For this reason substantial investments in technological $R \& D$ will not necessarily lead to successful innovations. A successful deployment strategy needs, among other things, a clear legislation regarding site selection, safety standards, monitoring, ownership etc. to gain public trust. Open communication with stakeholders, media and the general public concerning benefits, risks etc should therefore also be included in every CCS-project plan.

These notions are supported by the results from other studies, including Wustenhagen, Wolsink and Burer [17] who accentuate the need for policy makers and other stakeholders) to clarify who decides about what in the technology diffusion process. Thus, instead of primarily focusing on energy- and climate-related R\&D the processes by which the fruits of the research are deployed and the diffusion of new technologies takes place are also critical. If not, the result is an imperfect understanding of the institutional relationships that maintain the development, alternation and diffusion of energy technologies [15]. This in turn would hamper the development of appropriate policies to guide the system to meet new challenges.

Finally, though, the neoclassical emphasis on environmental externalities is a key also for the CCS technology. Technology policy is most effective - indeed only useful - if the emissions of carbon dioxide emissions carry a positive price (e.g., through a carbon tax or emissions trading). Such a policy creates a demand for carbon-free technology. Still, while 
carbon pricing must be the engine for reaching climate policy goals; technology policy can help that engine run faster and more efficiently, but it only helps if the engine is running [4]. In this sense an active technology policy is a complement, and not a substitute, to technology-neutral market-based instruments. CCS will require technology-specific policy attention, but the underlying demand for it will be low if carbon dioxide is not priced efficiently.

In Sweden the iron and steel industry has so far (along with the electric power sector) paid most attention to CCS. The Swedish steel industry is an active partner in the EU-wide research project Ulcos, which involves recirculation of carbon monoxide into the blast furnace and separating the carbon dioxide. The process is now being fine-tuned and the goal is to demonstrate a 70 per cent reduction of the carbon dioxide in steel production. Still, the necessary institutional set up (e.g., legislation, supporting research, organizational networks, informal norms etc.) needed to introduce the CCS technology on grander scale is still undeveloped in the country. Moreover, so far the European Emissions Trading System still provides relatively meagre incentives to increase demand for these technologies, and thus create incentives to invest in substantial $R \& D$ efforts.

\section{CONCLUding REMARKS}

The diffusion of new energy-efficient and carbon-free technology in process industries is a key policy goal. In this paper we have introduced two theoretical perspectives on the process of technological change, paradigms that offer partly contradicting but overall complementing lessons for the design of technology policy.

By examining two existing policies and one future technological challenge in the Swedish process industries, we concur that the neoclassical and the evolutionary approach can - used in combination - provide increased understanding of under which circumstances different public policies in the energy and environment field can have innovation-promoting impacts.

For instance, technological progress requires both $\mathrm{R} \& \mathrm{D}$ and learning and for this reason R\&D programs should typically not be designed in isolation from practical application. In addition, the gradual diffusion of a certain technology can reveal areas where additional $R \& D$ would be most productive. In the case of the environmental permitting system during the 1970s the cooperative approach of sharing information implied that new knowledge was advanced jointly and incrementally in close interaction between the company, the environmental authorities and the research institutions before the final permit was issued. In the Swedish pulp and paper case jointly funded $R \& D$ projects were often in full swing or planned for as new technology were brought up in connection to individual licensing processes. In this way research activities provided a direct catalyst to the policy process.

In practice thus the entire set up of the regulatory system (including informal norms, knowledge accumulation, and transfer of knowledge etc.) is decisive for the outcomes of environmental policies, and process industries are part of large networks whose interdependencies also may create deviations from perfectly efficient decision-making.

The Swedish experiences of the voluntary energy efficiency program PFE reveals some amount of evidence of behavioral failures (bounded rationality) on the part of individual firms, but it also displays a weak effect on technological innovation. In alternative institutional settings PFE (or similar programs) could possibly be combined with jointly (industry-state) funded R\&D projects that are advanced incrementally in interaction between the industry, the environmental authorities and relevant research institutes.

The innovation paths of the future are highly uncertain, but if these paths are explored jointly through coordinated public and private efforts (R\&D, learning etc.) to address societal concerns the resources allocated to the innovation processes can possibly be employed more efficiently. It is also important to acknowledge that innovation takes time, and for this reason extended compliance periods permit industrial firms to avoid errors and to mitigate diminishing returns of additional research and engineering manpower.

\section{REFERENCES}

Periodicals:

[1] K. Van Alphen, M. Hekkert, and W. Turkenburg, "Accelerating the Deployment of Carbon Capture and Storage Technologies by Strengthening the Innovation System," International Journal of Greenhouse Gas Control, vol. 4, pp. 396-409, 2010.

[2] A-K. Bergquist, and K. Söderholm (2011)."Green Innovation Systems in Swedish Industry, 1960-1989," Business History Review, vol. 68, pp. 677-698, 2011.

[3] G. Bonifati, "More is Different. Exaptation and Uncertainty: Three Foundational Concepts for a Complexity Theory of Innovation," Economics of Innovation and New Technology, vol. 19, pp. 743-760, 2010.

[4] C. Fischer, "Emissions Pricing, Spillovers, and Public Investment in Environmentally Friendly Technologies," Energy Economics, vol. 30, pp. 487-502, 2008.

[5] N. J. Foss, "Bounded Rationality in the Economics of Organisation: Much Cited and Little Used," Journal of Economic Psychology, vol. 24, pp. 245-64, 2003.

[6] E. Henriksson, and P. Söderholm, "The Cost-effectiveness of Voluntary Energy Efficiency Programs," Energy for Sustainable Development, vol. 13, pp. 235-243, 2009.

[7] R. B. Howarth, B. M. Haddad, and B. Paton, "The Economics of Energy efficiency: Insights from Voluntary Participation Programs," Energy Policy, vol. 28, pp. 477-486, 2000.

[8] A. B. Jaffe, and R. N. Stavins, "The Energy-Efficiency Gap. What Does It Mean?" Energy Policy, vol. 22, pp. 804-810, 1994.

[9] R. Kemp, and S. Pontoglio, "The Innovation Effects of Environmental Policy Instruments - A Typical Case of the Blind Men and the Elephant," Ecological Economics, vol. 72, pp. 28-36, 2011.

[10] T. J. Klette, J. Moen, and Z. Griliches, "Do Subsidies to Commercial R\&D Reduce Market Failures? Microeconometric Evaluation Studies," Research Policy, vol. 29, pp. 471-495, 2000.

[11] J. S. Metcalf, "Evolutionary Economics and Technology Policy," The Economic Journal, vol. 104, pp. 931-944, 1994.

[12] P. Mickwitz, H. Hyvättinen, and P. Kivimaa, "The Role of Policy Instruments in the Innovation and Diffusion of Environmentally Friendlier Technologies: Popular Claims versus Case Study Experiences," Journal of Cleaner Production, vol. 16(S1), pp. S162-S170, 2008.

[13] R. Nelson, and S. Winter, "Evolutionary Theorizing in Economics," Journal of Economic Perspectives, vol. 16, pp. 23-46, 2002.

[14] K. Rennings, "Redefining Innovation - Eco-innovation Research and the Contribution from Ecological Economics," Ecological Economics, vol. 32, pp. 319-332, 2000.

[15] A. D. Sagar, and J.P. Holdren, "Assessing the global energy innovation system: some key issues," Energy Policy, vol. 30, pp. 465-469, 2002. 
[16] D. J. Teece, G. Pisano, and A. Shuen, "Dynamic Capabilities and Strategic Management," Strategic Management Journal, vol. 18, pp. 509533, 1997.

[17] R. Wustenhagen, M. Wolsink, and M. J. Burer, "Social Acceptance of Renewable Energy Innovation: An Introduction to the Concept," Energy Policy, vol. 35, pp. 2683-2691, 2007.

Books:

[18] L. Lundqvist, The Hare and the Tortoise: Clean Air Policies in the United States and Sweden, Ann Arbor: The University of Michigan Press, 1980.

[19] B-Å. Lundvall, and S. Borrás, "Science, Technology and Innovation Policy," in The Oxford Handbook of Innovation, J. Fagerberg, D. Mowery, and R. Nelson, Eds., Oxford: Oxford University Press, pp. 599-631, 2005.

[20] R. Nelson (Ed.), National Innovation Systems, Oxford: Oxford University Press, 1993.

[21] R. Nelson, "Building Effective 'Innovation Systems' versus Dealing with 'Market Failures' as Ways of Thinking about Technology Policy," in The New Economics of Technology Policy, D. Foray, Ed. Cheltenham; Edward Elgar, 2009, pp. 7-16.

[22] J. Schumpeter, The Theory of Economic Development, Cambridge: Harvard University Press, 1934.

[23] G. Swann, The Economics of Innovation: An Introduction, Cheltenham: Edward Elgar, 2009.

\section{Technical Reports:}

[24] A-K. Bergquist, K. Söderholm, H. Kinneryd, M. Lindmark, and P. Söderholm, "Command-and-Control Revisited: Environmental Compliance and Innovation in Swedish Industry 1970-1990," CERE Working Paper 2012:2, Centre for Environmental and Resource Economics, Umeå University, Sweden, 2012.

[25] R. Brännlund, and T. Lundgren, "Environmental Policy without Costs? A Review of the Porter Hypothesis." Umeå Economic Studies No. 766, Department of Economics, Umeå University, Sweden, 2009.

[26] A. Mansikkasalo, G. Michanek, and P. Söderholm, "Industrins energieffektivisering: styrmedlens effekter och interaktion," Report 6460, Swedish Environmental Protection Agency, Stockholm, 2011.

[27] Swedish Energy Agency, Skattebefrielse på el - för effektiv energianvändning $i$ industrin, ET 2005:03, Eskilstuna, Sweden, 2005.

\section{Dissertations:}

[28] E. Henriksson, "Industrial Electricity Demand and Energy Efficiency Policy," Ph.D. dissertation, Economics Unut, Luleå University of Technology, Luleå, Sweden, 2010.

\section{BIOGRAPHIES}

Anna Mansikkasalo is a Ph.D. candidate in economics at Luleå University of Technology. She holds a Master's degree in economics from the University of Toledo, USA, and her research has been focused on industrial electricity demand and energy efficiency policy as well as on international trade in biofuels. Her publications have appeared in, for instance, Biomass \& Bionergy and Journal of Cleaner Production, and she has written policyoriented reports for the Swedish Energy Agency and the Swedish Environmental Protection Agency.

Patrik Söderholm has a Ph.D. in Economics and he is now Professor of Economcis at Luleå University of Technology. His research focuses on energy, resource and environmental economics, and he has done a lot of work on the impact of different energy and environmental policy instruments. $\mathrm{He}$ has been a Research Fellow at the Center for Energy and Environmental Policy Research, Massachusetts Institute of Technology (MIT), Cambridge, USA, and at the Environmentally Compatible Energy Strategies Project, International Institute for Applied Systems Analysis (IIASA), Laxenburg, Austria. Söderholm has published over 60 articles in peer-reviewed international journals and a large number of policy-oriented reports for, for instance, the Swedish EPA, the Swedish Energy Agency, the Nordic Council of Ministers, and the Ministry of Finance (Sweden), among others. 